\title{
FREQUENCY OF PRE-DIABETES, DIABETES MELLITUS IN NON-ALCOHOLIC FATTY LIVER DISEASE.
}

1. MBBS, FCPS

Associate Professor Medicine

Dow University of Health Sciences/ Civil Hospital Karachi.

2. MBBS, FCPS

Assistant Professor Medicine Dow University of Health Sciences/ Civil Hospital Karachi.

3. MBBS, FCPS

Professor Medicine

Dow University of Health Sciences/ Civil Hospital Karachi.

4. MBBS

Resident Nephrology Medicine Liaquat National Hospital Karachi.

Correspondence Address:

Dr. Ahsan Mobin

Dow University of Health Sciences/

Civil Hospital Karachi.

drahsanmobin@gmail.com

Article received on:

05/03/2020

Accepted for publication:

06/06/2020

\begin{abstract}
Rakhshinda Jabeen ${ }^{1}$, Ahsan Mobin ${ }^{2}$, Khalid Mehmood ${ }^{3}$, Syed Tajammul Ali ${ }^{4}$
ABSTRACT... Objectives: To determine the prevalence of diabetes mellitus and pre-diabetes among patients with NAFLD having BMI $\geq 25 \mathrm{~kg} / \mathrm{m}^{2}$ and compare it with the control group with non-fatty liver with same BMI. Study Design: Prospective, Analytical and Cross-sectional study. Setting: Department of Medicine, Civil Hospital Karachi. Period: January 2015 to October 2016. Material \& Methods: The study was conducted among two groups of patients, one with non-alcoholic fatty liver disease (NAFLD), having BMI of $\geq 25 \mathrm{~kg} / \mathrm{m}^{2}$ and they were compared with a control group having $B M l \geq 25 \mathrm{~kg} / \mathrm{m}^{2}$ but without fatty liver on ultrasound. Result: Out of 201 NAFLD participants, $82.08 \%$ had pre-diabetes and diabetes mellitus, while $82.51 \%$ of participants from non-NAFLD $(n=101)$ had pre-diabetes or diabetes mellitus. Insulin resistance was more common among non-NAFLD group than NAFLD group. Most of the metabolic parameter analysed in the study among two groups having slight difference, and they were statistically significant. Conclusion: Pre-diabetes and diabetes mellitus is a frequently reported problem among NAFLD and overweight/obese patients. Insulin resistance was found to be a significant predictor of diabetes mellitus.
\end{abstract}

Key word: $\quad$ Diabetes Mellitus, Insulin Resistance, NAFLD, Obesity, Pre-Diabetes.

Article Citation: Jabeen R, Mobin A, Mehmood K, Ali ST. Frequency of pre-diabetes, diabetes mellitus in non-alcoholic fatty liver disease. Professional Med $\mathrm{J}$ 2020; $27(8): 1703-1709$. DOI: 10.29309/TPMJ/2020.27.08.4617

\section{INTRODUCTION}

Diabetes Mellitus is a chronic health problem in every part of the world, including all age groups. At least 382million people ageing 40-59 years are affected by diabetes mellitus world over and going to be doubled by $2035 .{ }^{1}$ Estimated 1.5 million people died every year because of its complications. ${ }^{2}$ In Pakistan the prevalence of diabetes mellitus is $11.77 \%$, and Pakistan is at $6^{\text {th }}$ number among 10 countries with highest prevalence of diabetes mellitus. ${ }^{3}$

Non-alcoholic fatty liver disease (NAFLD) is a clinic-histopathological entity with histological features that resemble alcohol induced liver injury but can occurs in patients with little or no alcohol consumption. The pathogenesis of NAFLD has not fully elucidated. It encompasses a histological spectrum that ranges from fat accumulation in hepatocytes without concomitant inflammation or fibrosis to hepatic steatotsis with a necro inflammatory component that may or may not have associated fibrosis. The latter condition is termed as non-alcoholic steatohepatitis (NASH) ${ }^{4}$, which is now recognized as a leading cause of cirrhosis of liver. ${ }^{5}$ NAFLD is seen worldwide and is the most common liver disease in Western countries. The major risk factors for NAFLD includes central obesity, type 2 diabetes, dyslipidaemia and metabolic syndrome. ${ }^{6}$ In USA the prevalence of NAFLD is $10-46 \%$, and of NASH is $3-5 \%$, and they are biopsy proven ${ }^{7}$ which is a gold standard test for the diagnosis of fatty liver. Although ultrasound is more commonly used, because of increased risk and high expenditure of liver biopsy, especially in developing countries. ${ }^{8}$ Worldwide, the prevalence of NAFLD is $6-35 \%$. In one study, the prevalence of NAFLD among AsiaPacific region ranges from $5-30 \% .{ }^{9}$ Most patients of NAFLD are in their 40-50s, occurring equally in males and female. ${ }^{10}$ Patients with NAFLD and particularly of $\mathrm{NASH}$, often have one or more component of metabolic syndrome, including obesity, systemic hypertension, dyslipidaemia, 
insulin resistance or overt diabetes. ${ }^{11}$ There are also data suggesting NAFLD is associated with post cholecystectomy ${ }^{12}$, and those who never had surgery for gallstones do not develop fatty liver. Other conditions that may be associated with NAFLD are polycystic ovary syndrome, hypothyroidism, Obstructive sleep apnoea, hypopituitarism and hypogonadism. ${ }^{13}$ Most patients with NAFLD remain asymptomatic or sometimes may present with fatigue, malaise, vague right hypochondrial pain or hepatomegaly. There may be elevated liver enzymes including alanine aminotransferase, alanine aminoaspartate, alkaline phosphatase and gamma glutamyltransferase or hepatic steatosis on ultrasound. ${ }^{14}$ Serum ferritin greater than 1.5 times normal may be associated with higher nonalcoholic fatty liver disease activity score and with advanced hepatic fibrosis. ${ }^{15}$

Insulin resistance has a key role in the development of hepatic steatosis, and steatohepatitis. ${ }^{16}$ Obesity and type 2 diabetes are frequently seen in patients with NAFLD. Insulin resistance is also seen in patients of $\mathrm{NASH}$, who are not obese neither have impaired glucose tolerance. ${ }^{16}$ The reported prevalence of impaired glucose tolerance among obese children and adolescent ranges from $21-25 \%$, and the prevalence of type 2 diabetes mellitus is around $4 \% .{ }^{17}$ Fasting plasma glucose between 100-125 mg/dl, or HBA1C between 5.7 \& $6.4 \%$ suggests impaired glucose tolerance and should be further evaluated by an oral glucose tolerance. ${ }^{18}$

The aim of this study is to determine the frequency of pre-diabetes, diabetes mellitus in overweight or obese patients with or without NAFLD, and corelate it with insulin resistance. By early detection of pre-diabetes or diabetes mellitus will help to reduce not only the complications related to it but also the cost affecting the community and the patient itself.

\section{MATERIAL \& METHODS}

This prospective, analytical, cross-sectional study was conducted in a tertiary care Hospital of Karachi, during the period of January 2015 to October 2016. Total enrolled patients were segregated into two groups, having same age group between20-50 years. First group included had fatty liver on ultrasound having BMI $\geq 25 \mathrm{~kg} /$ $\mathrm{m}^{2}$, and the control group had BMI $\geq 25 \mathrm{~kg} / \mathrm{m}^{2}$ without fatty liver on ultrasound. Patients already having diabetes mellitus, hepatitis $B$, hepatitis $C$ and alcoholism were excluded from the study.

\section{Metabolic Parameters}

All patients were subjected to have fasting sugar, HBA1C, lipid profile, fasting insulin, liver function test and ultrasound liver. The ultrasound features of fatty liver include a hyperechoic liver where the echo-texture of the liver is brighter than the kidney and blurring of vascular markings. ${ }^{19}$ Hepatitis $\mathrm{B}$ and $\mathrm{C}$ were done in all patients. Homeostatic Model Assessment of Insulin Resistance (HOMAIR) was calculated to evaluate insulin resistance. It is categorized as normal insulin resistance when HOMA score is $<3$, moderate IR: between 3 and 5 , and severe IR when it is $>5$. A standard OGTT with $75 \mathrm{gm}$ glucose, was carried out in all patients. Fasting plasma glucose and impaired glucose tolerance are defined as a fasting glucose $\geq 100 \mathrm{mg} / \mathrm{dl}$ but $<126 \mathrm{mg} / \mathrm{dl}$, and a 2 -hour post load glucose on the OGTT of $\geq 140 \mathrm{mg} / \mathrm{dl}$ but $<200 \mathrm{mg} / \mathrm{dl}$ respectively. Participants were labelled as diabetic and pre-diabetics according to ADA criteria of $\mathrm{HbA} 1 \mathrm{C}$, one labelled as diabetic with $\mathrm{HbA} 1 \mathrm{C}$ of $\geq 6.5 \%$ and pre-diabetics when $\mathrm{HbA} 1 \mathrm{C}$ is between $5.7-6.4 \%$."

\section{Anthropometric Indices}

Weight was measured in $\mathrm{kg}$ using a calculated digital scale, while height was measured using a stadiometer. Waist circumference (WC) was measured by palpating the right iliac crest, crossing the mid axillary line and placing the measure around the trunk's body at minimal respiration on the standing position. Hip circumference $(\mathrm{HC})$ was assessed above the hips at maximum extension of the buttocks. The waist hip ratio (WHR) was the ratio between waist and hip curve. In relation to WHR, abdominal obesity is defined as WHR $>0.90$ for males and above 0.85 for females. BMI was calculated as the weight in $\mathrm{kg}$ divided by height in meter squared. For Asian population BMI criteria is different, people are labelled as pre-obese if falls between 25 to 29.9 
$\mathrm{kg} / \mathrm{m}^{2}$, and obese if BMI is greater than $30 \mathrm{~kg} / \mathrm{m}^{2}$."

\section{RESULT}

Out of 302, participants enrolled in the study, NAFLD was present in 201 patients having BMI $\geq 25 \mathrm{~kg} / \mathrm{m}^{2}$ and they were compared with 101 , non-fatty liver patients with same BMI. Out of 302 participants, 187 (61.9\%) were female and the maximum number of patients were from the age group $31-40$ years $(41.7 \%)$. The patient's demographic characteristics in both groups are summarized in (Table-I).
Regarding metabolic profile fasting glucose and 2 hours glucose were significantly higher in more than $50 \%$ of patients, in both study groups. Triglycerides and cholesterol were also raised in most of the patients in both study groups as shown in Table-II. Pre-diabetes was found in $45.27 \%$ and type 2 DM in $36.8 \%$ of participants having NAFLD, while in non-NAFLD group type 2 diabetes was more common than pre-diabetes (Figure-1). Insulin resistance is most significant in participants with increased BMI but almost having same percentage in both study groups (Figure-2).

\begin{tabular}{|c|c|c|c|c|c|}
\hline Variable & Properties & Group with NAFLD & Frequency\% & Group without NAFLD & Frequency\% \\
\hline \multirow{2}{*}{ Sex } & Male & 75 & $24.83 \%$ & 40 & $13.24 \%$ \\
\hline & Female & 126 & $41.72 \%$ & 61 & $20.12 \%$ \\
\hline \multirow{3}{*}{ Age } & 20-30 years & 43 & $14.24 \%$ & 32 & $10.59 \%$ \\
\hline & $31-40$ years & 87 & $28.80 \%$ & 37 & $12.25 \%$ \\
\hline & $41-50$ years & 72 & $23.84 \%$ & 31 & $10.26 \%$ \\
\hline \multirow{4}{*}{$\begin{array}{l}\mathrm{BMI}(\mathrm{kg} / \\
\left.\mathrm{m}^{2}\right)\end{array}$} & $25-29$ & 70 & $34.8 \%$ & 15 & $14.8 \%$ \\
\hline & $30-34$ & 68 & $33.8 \%$ & 30 & $29.7 \%$ \\
\hline & $>35$ & 63 & $31.34 \%$ & 56 & $55.44 \%$ \\
\hline & $>35$ & 51 & $25.3 \%$ & 49 & $48.51 \%$ \\
\hline \multirow{3}{*}{ WHR } & Low & 59 & $19.53 \%$ & 26 & $8.60 \%$ \\
\hline & Moderate & 46 & $15.23 \%$ & 12 & $3.97 \%$ \\
\hline & High & 96 & $31.78 \%$ & 63 & $20.86 \%$ \\
\hline
\end{tabular}

Table-I. Frequency of demographic and anthropometric profile among two groups.

\begin{tabular}{|l|c|c|c|}
\hline & NAFLD & Without NAFLD & P-Value \\
\hline Ohr sugar $(\mathrm{mg} / \mathrm{dl})$ & $106.4 \pm 24.02$ & $120.2 \pm 40.79$ & .000 \\
\hline 2hr sugar $(\mathrm{mg} / \mathrm{dl})$ & $157.9 \pm 91.54$ & $179.5 \pm 79.2$ & .000 \\
\hline HbA1C \% & $6.35 \pm 0.93$ & $6.67 \pm 1.31$ & .017 \\
\hline Fasting insulin (uU/ml) & $17.13 \pm 9.95$ & $14.96 \pm 8.34$ & .061 \\
\hline HOMA- IR & $4.56 \pm 3.04$ & $4.40 \pm 3.11$ & .677 \\
\hline WHR & $0.89 \pm 0.06$ & $1.71 \pm 8.06$ & .041 \\
\hline BMI $\left(\mathrm{kg} / \mathrm{m}^{2}\right)$ & $32.28 \pm 6.12$ & $35.48 \pm 5.56$ & .000 \\
\hline ALT IU & $38.56 \pm 21.74$ & $43.27 \pm 23.4$ & .085 \\
\hline ALP IU & $105.3=43.6$ & $132.3=60.2$ & .000 \\
\hline Cholesterol(mg/dl) & $205.0=92.06$ & $220.4-66.26$ & .008 \\
\hline Triglyceride (mg/dl) & $168.5=64.59$ & $172.0=57.8$ & .649 \\
\hline HDL (mg/dl) & $34.87 \pm 10.04$ & $31.94 \pm 9.65$ & .016 \\
\hline LDL $(\mathrm{mg} / \mathrm{dl})$ & $122.0=72.75$ & $126.0=48.96$ & .112 \\
\hline
\end{tabular}

Table-II. Frequency of anthropometric \& metabolic profile among both groups. 


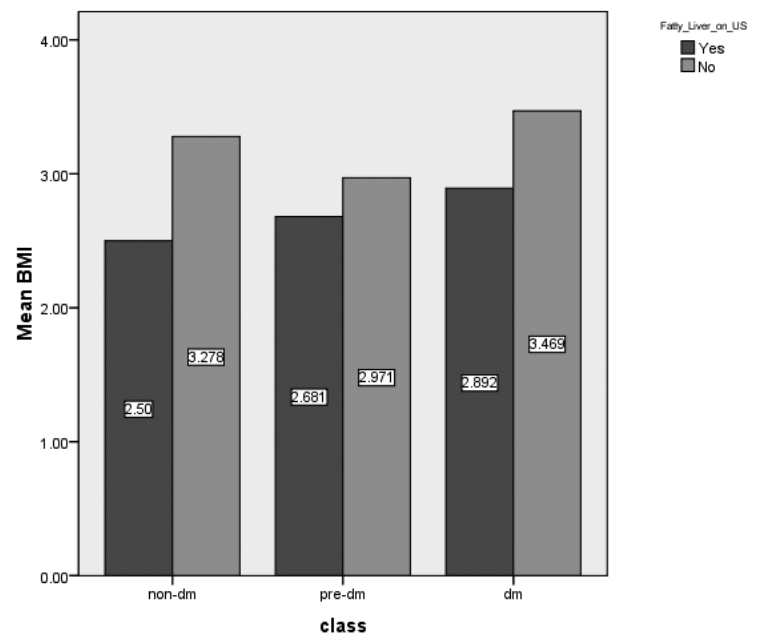

Figure-1. Classification of diabetes mellitus among both groups in relation to BMI.

\section{DISCUSSION}

Type 2 Diabetes Mellitus, is characterized by hyperglycaemia, insulin resistance, and relative impairment in insulin secretion. Prediction and prevention of type $2 \mathrm{DM}$, in general population is limited, but there are certain population who can be targeted including individuals who have increased fasting glucose, impaired glucose tolerance, obesity, immediate family members with type 2 Diabetes Mellitus. ${ }^{20,21}$

NAFLD currently is recognized as an important health problem, it encompasses a variety of liver pathologies including steatosis, non-alcoholic steatohepatitis, fibrosis, cirrhosis and even cancer. ${ }^{22}$ NAFLD is described by Ludwig, three decades ago and defined as fatty liver having liver fat $>5-10 \%$ of liver weight, and it must not be due to alcohol or other cause of steatosis. ${ }^{23}$ NAFLD is the most common cause of chronic liver disease in United States and is becoming common in South East Asia as well. The prevalence of NAFLD in South East Asia and South Asia is ranges from $5-30 \%$, and a Hospital based study done in Pakistan showing frequency of $14 \%{ }^{24}$ In India, the prevalence of fatty liver among healthy individual is $5-28 \%$. Indians having propensity of visceral fat accumulation. ${ }^{25}$ Although the risk for developing $\mathrm{DM}$, is commonly seen in patients with increased fasting glucose, impaired glucose tolerance and increased $\mathrm{HbA} 1 \mathrm{C}$, but it is more commonly seen among patients with $\mathrm{HbA1C}$ between $5.7-6.4 \%$

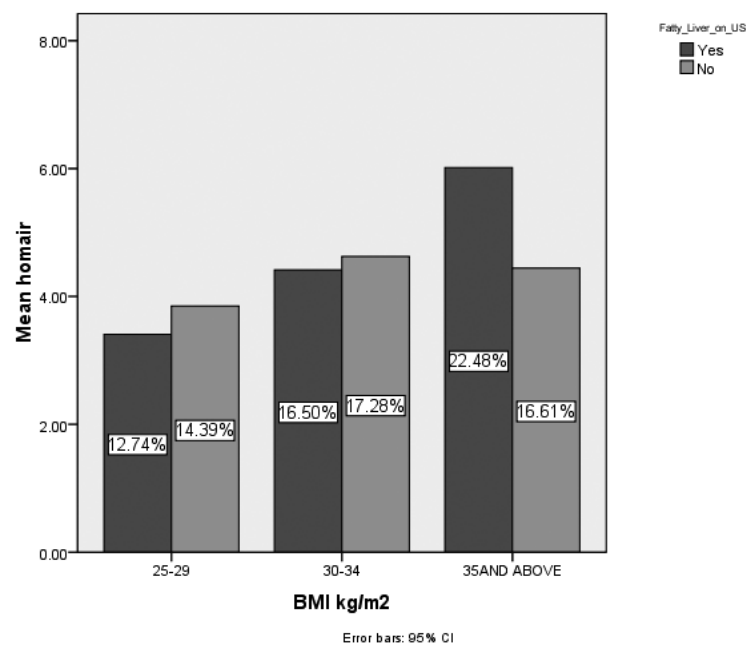

Figure-2. Co-relation of BMI with homa-ir in both groups.

(39-46 $\mathrm{mmol} / \mathrm{ml})$. The other additional feature is obesity i.e. BMI $\geq 25 \mathrm{~kg} / \mathrm{m}^{2}$ and the family history. ${ }^{26}$ In our study the fasting insulin and Homa-IR was slightly higher in NAFLD group with a $p$ value of 0.061 . All other metabolic profile is statistically significant in both groups, except triglycerides and ALT .Level of HbA1C is also raised in nonNAFLD group having a diabetic range which is against one study done in Iran in 2016. ${ }^{27}$ Studies have shown that prevalence of NAFLD increases with age which is also seen in our study. ${ }^{28,29}$ The same relationship has been seen with obesity, most of the participants included in our study with NAFLD had increased $\mathrm{BMI} \geq 25 \mathrm{~kg} / \mathrm{m}^{2}$. Its association has been seen in many studies, in Zelber-Sagi et.al, study, the mean BMI was 29.6+ 3.8 , which is quiet co relating with our study. ${ }^{30,31}$

The diagnosis of NAFLD, is made on abdominal imaging, but many patients seek medical attention due to raised liver enzymes along with fatigue and upper abdominal pain. ${ }^{32}$ There is a prevalence of deranged liver enzymes in $8 \%$ of population in $3^{\text {rd }}$ National Health and Nutrition Examination. Survey done in North America, most of these deranged liver enzymes is associated with NAFLD. ${ }^{33}$ These liver enzymes are typically normal or elevated by $<5$ times of upper limit of normal. ${ }^{34}$

The liver enzymes including alanine aminotransferase, gamma glutamyl transferase and alkaline phosphatase were increased 
in $25.49 \%, 25.1 \%$ and $8.2 \%$ respectively, is contradicting than the earlier published studies in which there is much significantly raised in NAFLD and or obese patients. ${ }^{35,36}$ Obesity is a state of excess adipose tissue, and is a prevalence is increasing Worldwide since 1980. The prevalence of obesity in Eastern Asia and Southern Asia is quiet low as compared to United States. ${ }^{37,38}$ Asia pacific society has incorporated anthropometric scale as a base of obesity in Asian population. A small increase in weight of 2-3 kg may lead to development of NAFLD, but more importantly it may present even with normal weight. ${ }^{39}$ Among Asian countries the highest obesity rate is seen in Thailand and Malaysia, while lowest is seen among Bangladesh, Vietnam and India. ${ }^{40}$ Among Asian countries rate of obesity is twice in females than that of males ${ }^{41}$, which is also seen in the current study with much higher numbers of female patients in the study. Obesity is associated with adverse outcome, weight loss may reduce many illnesses including diabetes mellitus, hypertension, dyslipidaemia, osteoarthritis and sleep apnoea syndrome and all these are associated with metabolic syndrome and NAFLD. ${ }^{32}$

\section{CONCLUSION}

Non-communicable diseases, including diabetes mellitus, hypertension, acute coronary syndrome and cancers are the major cause of deaths world over. In Pakistan, non-communicable diseases are the leading cause accounting $50 \%$ of total deaths in Pakistan. Diabetes ranked $4^{\text {th }}$ among all non-communicable diseases in Pakistan. It is now clear that NAFLD and insulin resistance have a close relationship, and insulin resistance is directly linked with hypertension, diabetes mellitus and atherosclerosis. These are the conditions that have much significant mortality and morbidity.

Copyright@ 06 June, 2020.

\section{REFERENCES}

1. International Diabetes Federation. IDF diabetes atlas. Sixth Edition 2013. [Cited on January 22, 2015.] Available from URL: http://www.idf.org/diabtesatlas.
2. World Health Organization Non-communicable diseases. Fact sheet Updated January 2015. [Cited on January 31, 2015.] Available from URL: http://www.who. int/features/factfiles/noncommunicable_diseases/en/.

3. Meo SA, Zia I, Bukhari IA, Arain SA. Type 2 diabetes mellitus in Pakistan: Current prevalence and future forecast. Systematic Review. J Pak Med Associ. December 2016; 66(12):1637-42.

4. Matteoni CA, Younossi ZM, Gramlich T. Non-alcoholic fatty liver disease: A spectrum of clinical and pathological severity. Gastroenterology 1999; 116:1413-6.

5. Caldwell SH, Oelsner DH, Lezzoni JC. Cryptogenic cirrhosis: Clinical characterization and risk factors for underlying disease. Hepatology 1999; 29:664-8.

6. Younossi ZM, Stepanoya M, Afendy M. Changes in the prevalence of the most common causes of chronic liver diseases in the United States from 1998 to 2008. Clin Gstroenterol Hepatol 2011; 9:524-7.

7. Williams CD, Stengel J, Asike MI. Prevalence of non-alcoholic fatty liver disease and nonalcoholicsteatohepatitis among a largely middleaged population utilizing ultrasound and liver biopsy: A prospective study. Gastroenterology 2011; 140:124-7.

8. Amarapurkar DN, Hashimoto E, Lesmana LA. How common in non-alcoholic fatty liver disease in the Asia-Pacific region and are there local differences? J Gastroenterol Hepatol 2007; 22:788.

9. Falck-Yetter Y, Younossi ZM, Marchesini G, McCullough AJ. Clinical features and natural history of nonalcoholic steatosis syndromes. Semin Liver Dis 2001; $21: 17-26$.

10. Marchesini G, Bugianesi E, Forlani GC. Non-alcoholic fatty liver, steatohepatitis, and the metabolic syndrome. Hepatology 2003; 37:917-23.

11. Hernaez R, Lazo M, Bonekamp S. Diagnostic accuracy and reliability of ultrasonography for the detection of fatty liver: a meta-analysis. Hepatology 2011 ; $54: 1082-$ 90.

12. Ruhl CE, Everhart JE. Relationship of non-alcoholic fatty liver disease with cholecystectomy in the US population. Am J Gastroenterol 2013; 108:952-8.

13. Chalasani N, Younossi Z, Lavine JE. The diagnosis and management of non-alcoholic fatty liver disease: Practice guideline by the American Gstroenterological Association for the study of Liver Diseases, and American College of Gastroenterology. Gastroenterology 2012; 142:1592-7. 
14. Bacon BR, Farahvash MJ, Janney CG, NeuschwanderTetri BA. Non-alcoholic steatohepatitis: An expanded clinical entity. Gastroenterology 1994; 107:1103-9.

15. Kowedly KV, Belt P, Wilson LA. Serum ferritin is an independent predictor of histologic severity and advanced fibrosis in patients with non-alcoholic fatty liver disease. Hepatology 2012; 55:77-81.

16. Chitturi S, Abeygunasekara S, Farrel GC. NASH and insulin resistance: Insulin hypersecretion and specific association with the insulin resistance syndrome. Hepatology 2002; 35:373-9.

17. Sinha R, Fisch G, Teague B. Prevalence of impaired glucose tolerance among children and adolescents with marked obesity. N Eng J Med 2002; 346-802.

18. Klish JW. Comorbidities and complications of obesity in children and adolescents. Upto date July 2018. Updated November 13, 2017.

19. Saadeh S, Younossi ZM, Reme EM. The utility of radiological imaging in non-alcoholic fatty liver disease. Gastroenterology. 2002; 123:745-750.

20. Taseer IH, Hussain L, Safdarl S, Mirbahar AM, Ahmed I. Frequency of non-alcoholic fatty liver disease (NAFLD) and its biochemical derangements in type -2 diabetic patients. Pak J Med Sci 2009; 25(5): 817820 .

21. Brancati $\mathrm{FL}, \mathrm{Kao} \mathrm{WH}$, Folsom AR. Incident type 2 diabetes mellitus in African American and white adults: The Atherosclerosis Risk in Communities Study. JAMA 2000; 283-2253.

22. Kistler KD, Brunt EM, Clark JM, Salis JF, Schwimmer JB. Physical activity recommendations, exercise intensity and histological severity of non-alcoholic fatty liver disease. Am J Gastroenterol 2011; 106:4608.

23. Kotronen A, Ykr-Jarvenin H, Mannisto S, Saarikoski L, et.al. Non-alcoholic and alcoholic fatty liver disease - two diseases of affluence associated with the metabolic syndrome and type 2 diabetes the FIND2D survey. BMC Public Health 2010; 10:237.

24. Niaz A, Ali Z, Nayyer S, Fatima N. Prevalence of NAFLD in healthy and young male individuals. ISRN Gastroenterol 2011; 2011:3633546.

25. Raji A, Seely EW, Arky RA, Simonson DC. Body fat distribution and insulin resistance in healthy Asian, Indians and Caucasians. J Clin Endocrinol Metab 2001; 86: 5366-71.
26. Barrit AS, Dellon ES, Kozlowski T, Gerber DA, Hayashi $\mathrm{PH}$. The influence of non- alcoholic fatty liver disease and its associated co morbidities on liver transplant outcomes. J Clin Gastroenterol 2011; 45(4): 372-8.

27. Ghanaei FM, Jafarinejad A, Roshan ZA, Khosravi $H$. Non-Alcoholic Fatty Liver Disease and Prediabetes. JPMS, January-march, 2016; 6(1):6-9.

28. Bahcecioglu IH, Koruk M, Yilmaz O, Bolukbas $F$, Tuncer I. Demographic and clinicopathological characteristics of non-alcoholic fatty liver disease in East-Southeastern Antolia regions in Turkey. Medical Principles and Practice 2006; 15(1):561-5.

29. Schwimmer JB, Deutsch R, Finegold MJ, Lavine JE. Influence of gender, race, and ethnicity on suspected fatty liver in obese adolescents. Pediatrics 2005; 115:561-5.

30. Zelber-Sagi S, Lotan R, Shibolet O, Webb M, Buch A, Nitzan-Kaluski D, et al. non-follow-up. Liver International 2013; 33(9):1406-12.

31. Lankarani KB, Ghaffarpasand F, Mahmoodi M, Lotfi M, Zamiri N, Heydari ST, et al. non-alcoholic fatty liver disease in southern Iran: A population-based study, Hepatitis monthly 2013; 13(5): e9248.

32. Chittun S, Farrel GC, Hashimoto E,Siabara T, Lau GK, Sollano JD. Non-alcoholic fatty liver disease in the Asia-Pacific region: definition and overview of proposed guidelines. J Gastroenterol Hepatol 2007; 22:778-87.

33. Clark JM, Brancati FL, Diehl AM. The prevalence and aetiology of elevated aminotransferase levels in the United States. Am J Gastroenterol 2003; 98:857-63.

34. Ramesh S, Sanyal AJ. Evaluation and management of non-alcoholic steatohepatitis. J Hepatol 2005; 98:9607.

35. Ortiz-Lopez C, Lomonaco R, Orsak B, Finch J, Chang $Z$, Koxhunov VG, et al. prevalence of prediabetes and diabetes and metabolic profile of patients with nonalcoholic fatty liver disease (NAFLD). Diabetes Care 2012; 35(4): 873-8.

36. Sign SP, Singh A, Pati GK, Misra B, Misra D, Kar SK, et al. A study of prevalence of diabetes and pre-diabetes in patients of non-alcoholic fatty liver disease and the impact of diabetes on liver histology in coastal eastern India. J Diabetes Mellitus 2014; 4(4):290-6.

37. Kim DM, Ahn CW, Nam SY, Prevalence of obesity is Korea, Obes Rev. 2006; 117-121. 
38. Aekplakorn W, Chaiyapong Y, Neal B, ChariyalertsakS, Kunanusont C, Phoolcharoen W. Prevalence and determinants of overweight and obesity in Thai results: Results of the Second National Health Examination Survey. J Med Assoc Thai. 2004; 87:685693.

39. Chitturi S, Wong VW, Farrell G. Non-alcoholic fatty liver in Asia: Firmly entrenched and rapidly gaining ground. J Gastroenterol Hepatol 2011; 26 Suppl 1: 16372.
40. Wong RJ, Ahmed A. Obesity and non-alcoholic fatty liver disease: Disparate associations among Asian populations. World J. Hepatol. 2014; 6:263-273.

41. Ashtari S, Pourhoseingholi MA, Zali MR. Non-alcohol fatty liver disease in Asia: Prevention and planning. World J Hepatol 2015 Jul 8; 7(13):1788-96.

\begin{tabular}{|c|c|c|c|}
\hline \multicolumn{4}{|c|}{ AUTHORSHIP AND CONTRIBUTION DECLARATION } \\
\hline Sr. \# & Author(s) Full Name & Contribution to the paper & Author(s) Signature \\
\hline 1 & Rakhshinda Jabeen & $\begin{array}{l}\text { Conception and design, Statistical } \\
\text { expertise, Critical revision of the } \\
\text { article for important intellectual } \\
\text { content. }\end{array}$ & Lavenshunis \\
\hline 2 & Ahsan Mobin & $\begin{array}{l}\text { Data collection, Critical revision of } \\
\text { the article for important intellectual } \\
\text { content. }\end{array}$ & 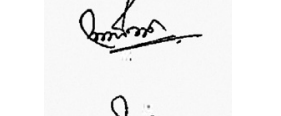 \\
\hline 3 & Khalid Mehmood & $\begin{array}{l}\text { Data collection, Critical revision, } \\
\text { Drafting of the article. }\end{array}$ & - \\
\hline 4 & Syed Tajammul Ali & Data collection. & \\
\hline
\end{tabular}

